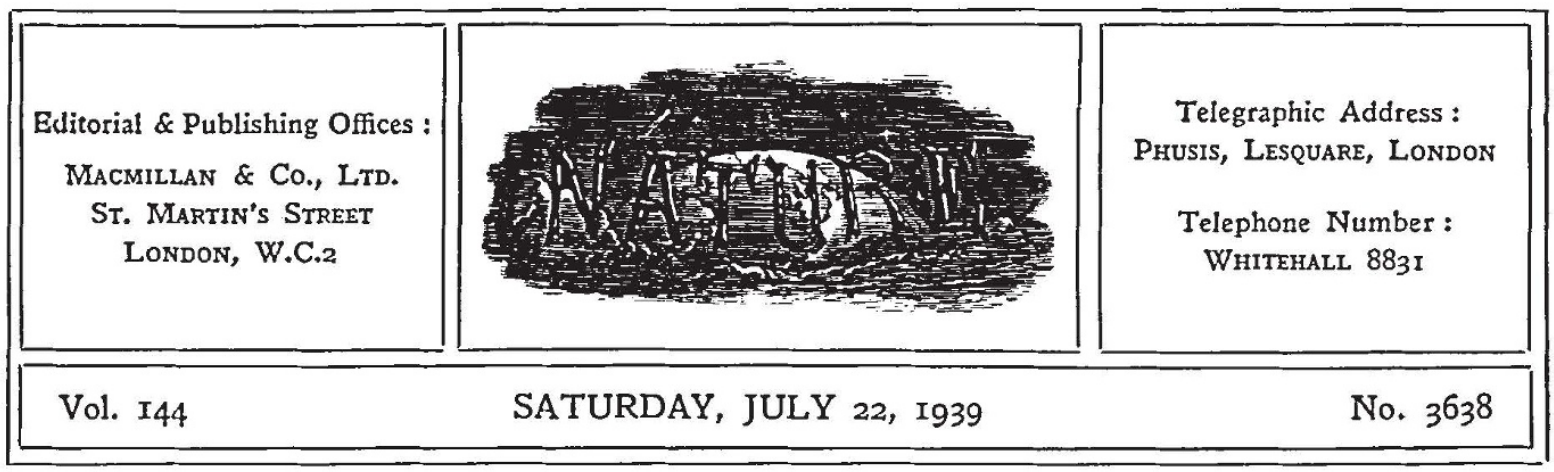

\title{
SCHOOL BIOLOGY AND CITIZENSHIP
}

IN Great Britain and in other countries the present century, and particularly the last twenty years, have seen great efforts made to improve the school curriculum. It is true that these efforts have been largely experimental, and it cannot be said that they have produced that balanced course which would meet with general, even if not universal, approval. That is partly due to the difficulty of viewing with detachment the traditional courses through which we ourselves have passed, and partly to the endeavour to create new courses by interpolation of new subjects without due regard to the unity of the educational scheme as a whole.

Yet behind these efforts there are apparent ideals which in the end may greatly modify education in schools of all degrees. One affects the pupil as an individual, for the clear trend of modern education is to lay more stress upon the personality, which must be developed through its own response and through the encouragement of initiative. The biological truth that it is not so much the impression from without, but the response of the organism from within which counts in development, appears to be a sound foundation for educational method.

The second ideal has been forced to the front by the antagonisms which have become so insistent within the nations themselves, and it affects the pupil not as an individual but as a member of society. It asks for knowledgeable citizens, able to see and think for themselves, to balance opposing points of view and to make their own decisions, self-confident enough in their own judgment to be independent. It implies that the schools must plan their courses deliberately to contribute to the foundation of sound citizenship.
These thoughts were evidently in the minds of speakers taking part in the educational discussions which had a prominent place in the Ninth Imperial Social Hygiene Congress held in London last week. There the emphasis was laid upon the subject of biology, and while this is but one of the arts and sciences which must contribute to the development of youth, it embraces interests and methods which offer advantages of their orn. Particularly it presents an easy and natural gradient to human affairs, from the discussion of the common pro. perties of all living things and their inter-relations to the dependence of man upon common plants and animals, and so to his general relation to his environment. But part of the environment of man is man himself, and so a logical scheme of biological studies must in the end include not only aspects of human physiology but also a wider human biology, objective studies of human populations, human relationships, racial significances or perhaps insignificances, and the like.

A new and forcible argument for the universal teaching of biology in schools was advanced by Prof. James Ritchie in an address upon the "Supply and Training of Teachers in Biology". Sir Richard Gregory and others have in the pages of NATURE and elsewhere directed attention to the difficulties which have arisen between the nations because of the inordinate progress of scientific knowledge and invention in recent years, and the failure of mankind to assimilate these advances and weld them into a social and moral unity. Prof. Ritchie suggested that the failure is partly due to the exclusiveness of science, and that the remedy lies in the creation of a national appreciation of the social and moral implications of scientific knowledge. So soon as biological knowledge, and 
that embraces knowledge of human relations, becomes a common heritage of every child in the country, the nation would be conditioned for that blending of knowledge and moral sense which has lagged behind in this age of scientific progress.

If that prognosis be accurate, the introduction of biological teaching into all schools, under graded schemes covering the school life of a pupil, becomes a matter of national importance. Distinct progress has been made in Great Britain since the Zoology Organization Committee of the British Association reported in $\mathbf{1 9 2 1}$ that "it is a common fact that in England alone, among civilized countries, a boy and girl can reach the age of 18 or 19 years and leave school without having received any school instruction in animal physiology or the natural history of animals". At that time, many lands abroad had already estab. lished graded courses in biology which were shared in, not by a few scholars passing on to a specialized course in science in the universities, but by all pupils without exception. Some of the lee-way has been made up in Great Britain, particularly in England and Wales, though Scotland still seems to lag behind; but much has to be done before biology can be looked upon as a school subject universally adopted.

Yet if the subject holds in its interests and content the values that have been claimed for it, its introduction and prosecution in the proper spirit in schools is a matter of national import, which máy have beneficial repercussions towards the amelioration of social relations within the nation and between nations. Several speakers in the course of the discussions at the Social Hygiene Congress pointed out that upon the universities lies a heavy responsibility in this respect, that they undertake the training of the majority of the men and women who as teachers are to become the disseminators of biological knowledge through. out the nation; and it was suggested that, with a few exceptions, they have failed to live up to their responsibilities. University courses, particularly in zoology, are not adapted to give the student who is to become a teacher that contact with animals in their relations to environment and to each other which must form a groundwork in school teaching.

Furthermore, the universities have unconsciously done an ill-turn to the service of biology as a national asset by favouring research at the expense of school teaching; the best men are usually guided into the paths of scientific investigation, and second raters are often looked upon as good enough for the services of scientific education and the investigations it so badly needs. Yet if there is any situation that requires re-examination in the nations to-day, it is the chasm between scientific progress and the knowledge and spirit to use that progress solely for the benefit of mankind. No certain method of bridging this gap is evident. But any reasonable suggestion is worthy of trial, and if, as has been suggested, the national teaching of biology is likely to create a scientific attitude of mind such that appreciation of the social and moral implications of science becomes second nature, then the best men and women are not too good for a task upon which may depend the ultimate progress of humanity.

\section{ANALYTICAL ASTROPHYSICS}

An Introduction to the Study of Stellar Structure

By S. Chandrasekhar. (Astrophysical Monographs sponsored by The Astrophysical Journal.) Pp. ix +509. (Chicago: University of Chicago Press ; London: Cambridge University Press, 1939.) 50s. net.

$\mathrm{E}^{\mathrm{B}}$ DDINGTON'S 'Internal Constitution of the Stars" was published in 1926 and gives what now ranks as a classical account of his own researches and of the general state of the theory at that time. Since then, a tremendous amount of work has appeared. Nuch of it has to do with the construction of stellar models with different equations of state applying in different zones. Other parts deal with the effects of varying chemical composition, with pulsation and tidal and rotational distortion of stars, and with the precise relations between the interior and the atmosphere of $a$ star. The striking feature of all this work is that so much can be done without assuming any particular mechanism of stellar energy-generation. Only such very comprehensive assumptions are 